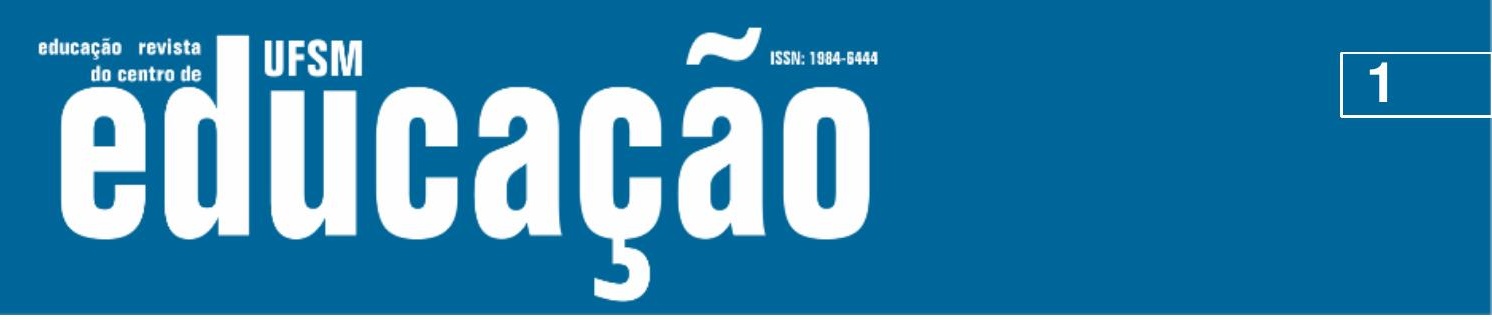

ISSN: 1984-6444 | http://dx.doi.org/10.5902/1984644434409

\title{
Metacognição e a experimentação investigativa: a construção de categorias interativa dialógicas
}

\author{
Metacognition and inquiry experimentation: the construction of dialogic \\ interactive categories
}

Carlos Jose Trindade da Rocha

Universidade Federal do Pará

João Manoel da Silva Malheiro

Universidade Federal do Pará

Recebido em 31 de outubro de 2018

Aprovado em 12 de novembro de 2018

\section{RESUMO}

Metacognição na experimentação investigativa é um processo que envolve conhecimentos procedimentais e atitudinais necessários para a formação crítica científica. A experimentação investigativa (EI) como abordagem didática, pode desenvolver nos alunos a alfabetização científica, potencializando a metacognição. Nessa perspectiva, objetivou-se apresentar proposições de instrumento de análise com potencial metacognitivo com foco nas interações discursivas originadas de atividades experimentais investigativas realizadas em um Clube de Ciências. A metodologia de abordagem qualitativa concebe a pesquisa participante, para o desenvolvimento de práticas epistêmicas com formas interativas mais gerais do processo discursivo baseadas na metacognição. A tal efeito, o instrumento possibilita aplicação e análise de categorias e intervenção pedagógica em sequências de ensino investigativo (SEI), através da resolução de problemas reais. A definição de categorias contribui para compreender que o trabalho pedagógico deve acontecer de maneira interativa e colaborativa, a fim de analisar o entendimento da complexa dinâmica envolvendo os processos interativos dialógicos que têm motivado o desenvolvimento de pesquisas relacionadas ao discurso entre professores e alunos, e seu impacto na condução de argumentações no contexto do ensino de Ciências.

Palavras-chave: Metacognição; Experimentação investigativa; Ciências.

\section{ABSTRACT}

Metacognition in inquiry experimentation is a process that involves procedural and attitudinal knowledge required for critical scientific formation. Inquiry experimentation (EI) as didactic approach, can develop in students scientific literacy, potentializing metacognition. In this perspective, the objective was to present propositions of analysis instrument with metacognitive potential focusing on the discursive interactions originated from inquiry experimental activities carried out in a Science Club. The methodology of qualitative approach conceives the new trends of active methodologies, for the development of epistemic practices with more general 


\section{工 WFM Eutlatăo

ISSN: 1984-6444 | http://dx.doi.org/10.5902/1984644434409

interactive forms of the discursive process based on metacognition. To this end, the instrument allows the application and analysis of categories and pedagogical intervention in Sequences of Investigative Teaching (SIT), through the resolution of real problems. The definition of categories contributes to the understanding that pedagogical work must take place in an interactive and collaborative way in order to analyze the understanding of the complex dynamics involving dialogic interactive processes that have motivated the development of research related to the discourse between teachers and students and their impact in the conduct of arguments in the context of science teaching

Keywords: Metacognition; Inquiry Experimentation; Sciences.

\section{Introdução}

Pesquisadores e educadores das mais diversas áreas do conhecimento têm demonstrado crescente interesse em estudar maneiras de promover a construção do conhecimento e o desenvolvimento das habilidades de raciocínio de seus alunos. Estudos relacionados em promover a metacognição (ROCHA; MALHEIRO, 2018; LOCATELLI, 2014; GIRASH, 2014; MATHABATHE; POTGIETERB, 2014) vêm mostrando o enorme potencial de organização discursiva, já que leva os envolvidos a movimentos de revisão e de construção de conhecimentos a partir da reflexão sobre seus próprios pensamentos.

Desta forma, na experimentação investigativa, essas abstrações cognitivas devem ser promovidas pelo professor com alguns cuidados, para que o debate não se transforme em um monólogo. Promover a metacognição na experimentação investigativa, não é tarefa fácil, pois demanda saber perguntar e saber ouvir (ROCHA; MALHEIRO, 2018).

Quanto ao desenvolvimento metacognitivo de alunos envolvidos em situações de experimentação, o presente estudo se insere no esforço de ampliação dessas reflexões no domínio das ciências, buscando contribuir para o entendimento da metacognição na construção de um ambiente de reflexividade experimental no domínio das Ciências, intencionando um ensino mais eficaz, ao propor uma ferramenta analítica de categorias que ajude a compreender, melhor o know-how metacognitivo em atividades experimentais investigativas.

Esta proposta de construção de um instrumento de categorias de análises para estudo na experimentação investigativa se originou e foi iniciado em uma proposta de 


\section{F HEM eltibarao

ISSN: 1984-6444 | http://dx.doi.org/10.5902/1984644434409

pós-doutorado articulados a atividades em espaços não formais de educação científica. A proposta vem se consolidando nos trabalhos desenvolvidos em um Clube de Ciências de uma universidade federal no norte do Brasil como laboratório de pesquisa, envolvendo a Sequência de Ensino Investigativo (SEI), concebidas por Carvalho (2013) e adaptadas por Rocha (2018).

Na SEI, Rocha (2018) propõe quatro etapas: 1) Distribuição do material e proposição de problema; 2) Identificação e exploração de ideias/previsões dos alunos; 3) Elaboração de possíveis planos de ações e experimentação do planejado; e 4) Escrever e desenhar, associando com a realidade; intencionam principalmente conhecimentos procedimentais, atitudinais e comunicacionais em ações de reflexões ocorridas durante atividades experimentais investigativas para a resolução de um problema real, com debates contextualizados.

Neste delineamento emerge a proposta de instrumento de análise metacognitivo, se propondo a explicitar a seguinte questão: De que maneira podem se estabelecer processos metacognitivos e a construção de esquemas argumentativos, a partir da realização de atividades experimentais investigativas por crianças participantes de um Clube de Ciências, ao buscarem soluções para um problema real?

A experimentação, num viés investigativo, no cotidiano da sala de aula exige leitura crítica do mundo, capacidade argumentativa que envolve o domínio da linguagem (LUCA; SANTOS, 2016; ALMEIDA, 1998). A experimentação aqui proposta, está definida na perspectiva de uma abordagem didática com potencial metacognitivo e desta, com outras áreas do saber.

Deste modo, defendemos que a experimentação investigativa realizada em clubes de ciências (e possivelmente outros ambientes não formais de ensino), pode possibilitar o desenvolvimento de um importante espaço para o desenvolvimento de pesquisa nas mais diversas vertentes de práticas epistêmicas e pedagógicas. Dessa forma, em suas atividades privilegiam as discussões, os debates, as exposições de ideias, os conhecimentos prévios e as percepções dos alunos diante de um fenômeno ou conceito. 


\section{Autดaคูão}

ISSN: 1984-6444 | http://dx.doi.org/10.5902/1984644434409

O que buscamos com este trabalho é identificar os qualificadores presentes na metacognição externalizadas por alunos e professores durante as atividades experimentais investigativas, especialmente aquelas que nos ajudem a compreender a forma como os sujeitos envolvidos organizam os seus saberes, por ocasião da realização de uma SEI que objetiva a resolução de problemas. Além dessa perspectiva, almejamos entender a como se dá o processo de autoconhecimento se conhecer.

\section{Metacognição e dimensão interativa}

Originalmente utilizado por Flavell (1979), o termo metacognição é compreendido enquanto processo no qual os indivíduos monitoram e controlam seu próprio funcionamento cognitivo. Para Chiaro e Aquino (2017) o foco de estudo desse autor é cognitivista e, portanto, está na esfera das operações mentais.

Num primeiro momento, considerar a metacognição como um "pensar sobre o pensamento" é interessante, entretanto, é necessário um aprofundamento e uma visão mais ampla dessa definição, já que ela é bem mais complexa e possui muitos outros aspectos (LOCATELLI, 2014, p. 24).

Em concordância com White (1988) e Brown (2006) a metacognição permite a tomada de consciência do seu próprio conhecimento. Neste estudo, o foco recai no papel da interação dialógica da comunicação, em geral, no desenvolvimento cognitivo, uma vez que aqui se assume uma relação contextualizada e interdisciplinar da experimentação.

Assim como muitos outros termos, considera-se que a metacognição é um termo polissêmico. Conforme já assinalamos, não é algo visível. Como Locatelli (2014), podemos assumir a metacognição como uma série de processos envolvendo o monitoramento e o repensar dos próprios conhecimentos, levando gradativamente a um aumento na autonomia de estudar e aprender.

Complementando essas ideias, ressaltam-se os temos "meta" e "cognição". O status de "meta" seria algo como pensar sobre os processos de conhecer, incluir estados mentais, como pensar, raciocinar, imaginar, discursar. Portanto, os processos cognitivos e metacognitivos são diferentes (LOCATELLI, 2014). 


\section{usm

ISSN: 1984-6444 | http://dx.doi.org/10.5902/1984644434409

As habilidades cognitivas são necessárias para fazer a experimentação, ao passo que com as metacognitivas entende-se como aquelas em que a experiência foi feita, refletindo-se sobre ela. Em determinado momento se pode realizar a experimentação e resolver um problema proposto (cognição) e, num outro instante, refletir sobre ele, repensando as etapas de análise (metacognição), que podem ocorrer durante a SEI.

Ao tentar compreender as dimensões das interações que ocorrem entre professores e alunos, encontramos em Monteiro e Teixeira (2004) e Compiani (1996), análises concisas das interações gerais que acontecem durante o processo discursivo em sala de aula. A elaboração de categorias permite compreender melhor o papel da fala dos alunos e do professor. São identificadas pelos autores como: Solicitação de Informações, Fornecimento de Informações, Reespelhamento, Problematização, Reestruturação e Recondução (Figura 1).

Figura 1 - Categorias interativas dialógicas

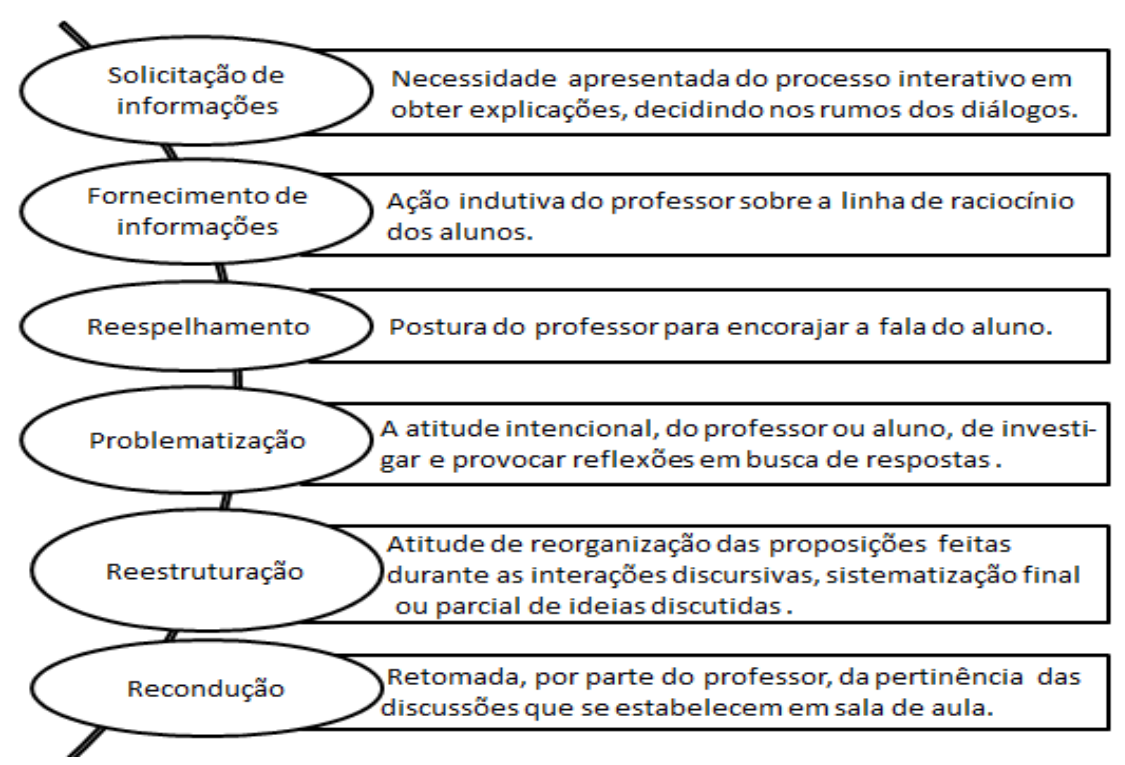

Fonte: Monteiro; Teixeira (2004) e Compiani (1996). Adaptado.

Os autores entendem que, quando não há clareza nas ideias expostas, e quando não houver discussão que explicitem um determinado fato, o fornecimento de informações se dá por intermédio de pistas na exposição direta de ideias, o que define 


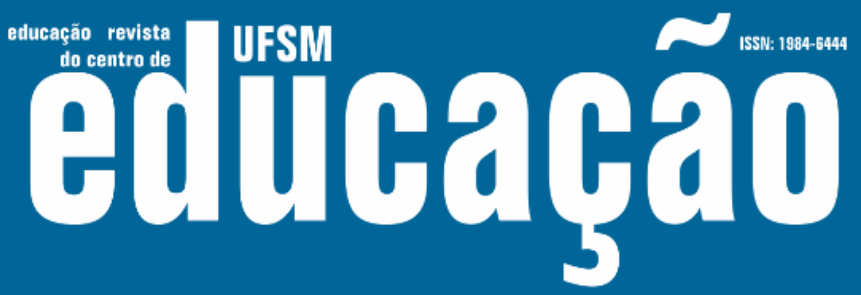

ISSN: 1984-6444 | http://dx.doi.org/10.5902/1984644434409

a atitude do professor em oferecer elementos para o raciocínio do aluno, possibilitando conduzi-lo à resolução de um problema.

Dentre as características de interação, ainda se destaca o Remodelamento de informações entre a exposição direta de ideias manifestadas pelos estudantes e o Fornecimento de Pistas pelo professor. No Remodelamento, o professor chama atenção para os pontos de vista dos alunos que, pela falta de maior precisão e detalhes em seus argumentos, oferece informações conceituais adicionais a eles, dando nitidez e precisão a uma ideia mais próxima da visão científica. O professor, durante o Remodelamento, investido de autoridade discursiva, repete ou gesticula favoravelmente ao que os alunos argumentam, o que contribui para dar legitimidade à ideia do aluno (ROCHA; MALHEIRO, 2018).

Na categoria Problematização, os autores incluem as ideias contrapostas, que objetivam ressaltar alguma contradição ou provocar conflitos importantes para a integralização de aula. Já na reestruturação, se tem a sistematização final, em que aparece uma Recapitulação a fim de generalizar as ideias dos alunos para encerrar a questão.

A Recondução realça a dimensão de pertinência que possibilita ao professor identificar os rumos dos diálogos e sua evolução dentro do objetivo proposto no estudo, podendo intervir nas discussões, caso encontre derivações não pertinentes.

Cabe ressaltar que as interações em sala de aula propõem uma classificação do dizer do professor em: argumentação retórica, socrática e dialógica (BOULTER; GILBERT, 1995). Assim, a ideia de argumentação nos tipos de falas entre professores e alunos apresentam conexões declarativas posicionadas.

Corroborando a assertiva de Boulter e Gilbert (1995), na argumentação retórica o pensamento e a opinião dos ouvintes não são levados em consideração; apresenta uma estrutura linear onde o professor busca persuadir uma audiência receptiva a transmissão do conteúdo. No cenário de argumentação socrática, o tipo de discurso dirigido é conduzido pelo professor, reformulando questões para obter respostas esperadas pelos alunos. Na argumentação dialógica, o professor se propõe a construir consensos, para que os alunos possam discutir e criar questões investigativas. 


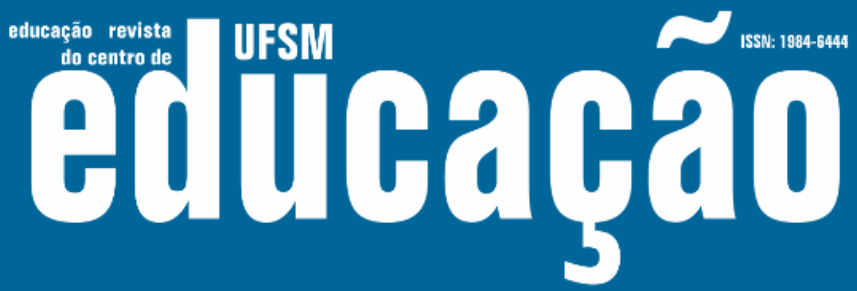

ISSN: 1984-6444 | http://dx.doi.org/10.5902/1984644434409

Nesse padrão discursivo, quem desempenha o papel ativo nas atividades é o aluno. $O$ centro das atenções está em suas falas, ideias e conclusões, que devem ser garantidas e provocadas pelo professor às conclusões dos alunos, fazendo-os perceber as virtudes e as falhas das hipóteses levantadas, propiciando, uma interação, que permita um compartilhamento de ideias a serem consideradas coletivamente (ROCHA; MALHEIRO, 2018). Assim, conforme Monteiro e Teixeira (2004) parecem ser convenientes caracterizar a Instigação, Contraposição, Organização, Recapitulação, Recondução e Fala Avaliativa, que serão mais bem definidas mais adiante.

Neste contexto, a proposta deste trabalho se baseia em experiências bemsucedidas de popularização e divulgação da ciência em espaços não formais de ensino (ROCHA; MALHEIRO, 2017) da Região Nordeste do Estado do Pará, envolvendo experimentações investigativas. É crescente o número de trabalhos sobre metacognição (CLEOPHAS; FRANCISCO, 2018; LOCATELLI, 2014; MEDEIROS; SILVA; LOCATELLI, 2018; PORTILHO; MEDINA, 2016) e acerca da experimentação investigativa no ensino de Ciências (SEDANO; CARVALHO, 2017; SASSERON; DUSCHL, 2016; CARVALHO, 2013) que entendem que na experimentação investigativa se exige uma atividade que permita interação entre os esquemas mentais daquele que aprende com o mundo científico e com características do contexto social em que ocorre o ensino.

Destaca-se que as ações, realizadas em Clubes de Ciências (ROCHA; MALHEIRO, 2017; PRÁ; TOMIO, 2014; OLIVEIRA, 2010; GONÇALVES, 1993) mostram que há formas inovadoras de se ensinar Ciências, em que a proposição de soluções de problemas, na experimentação investigativa (SILVA, MACHADO; TUNES, 2010; CARVALHO, 2009; KELLY, 2008), são instrumentos importantes a serem utilizados pelos professores, para melhorar e tornar mais interativo o ensino de Ciências (MALHEIRO; FERNANDES, 2016; SILVA, 2015).

Portanto, apesar de todas as dificuldades existentes na educação brasileira, entendemos ser possível criar condições para que o aluno seja capaz de desenvolver processos metacognitivos, a partir de estudos da própria realidade. Os desafios são 


\section{Autตaดูão}

ISSN: 1984-6444 | http://dx.doi.org/10.5902/1984644434409

muitos e os esforços a serem feitos precisam ser continuados para conferir capacidade de transformações interativas entre professores e alunos.

\section{Dimensão experimental investigativa}

Os estudos sobre as diferentes práticas pedagógicas vem sendo bastante discutidos nas últimas décadas (MALHEIRO, 2016; ROCHA, 2015; SILVA; ZANON, 2000, PRAIA, CACHAPUZ; GIL-PÉREZ, 2002; AXT, 1991). Dentre eles, destaca-se o uso das atividades experimentais, consideradas por muitos professores, como indispensáveis para o bom desenvolvimento do ensino.

Considerando esse aspecto, a experimentação no ensino pode ser entendida com uma atividade que permite articulação entre fenômenos e teorias. Desta forma, o aprender Ciências deve ser uma relação constante entre o fazer e o pensar (SILVA; MACHADO; TUNES, 2010).

Há alguns tipos de classificações para os procedimentos experimentais (GONÇALVES; GALIAZZI, 2006; HODSON, 1996; AXT, 1991;), também são considerados por pesquisadores da área (ROCHA; ALTARUGIO; MALHEIRO, 2017; SASSERON, 2013; SILVA; MACHADO; TUNES, 2010; CARVALHO, 2013) como atividades didáticas de valor inestimável para despertar o interesse dos estudantes e, consequentemente, para dinamizar a construção de novos conhecimentos científicos (CARVALHO, 2013).

O recurso do trabalho experimental se faz necessário, principalmente com o objetivo de extrair informações epistemológicas relevantes que podem ser evidenciadas durante esses procedimentos (CHALMERS, 1999). Para isso, é fundamental ter a percepção da importância que a experimentação desempenha, não só como elemento estimulador para despertar o interesse dos alunos pelas discussões acerca dos conteúdos específicos das Ciências, mas para ter consciência da necessidade de seu contínuo desenvolvimento (MALHEIRO, 2016).

Utilizar experimentos como ponto de partida, para desenvolver a compreensão de conceitos, é uma forma de levar o aluno a participar de seu processo de aprendizagem, sair de uma postura passiva e começar a agir sobre o seu objeto de estudo, relacionando esta perspectiva com acontecimentos atuais e buscando as 


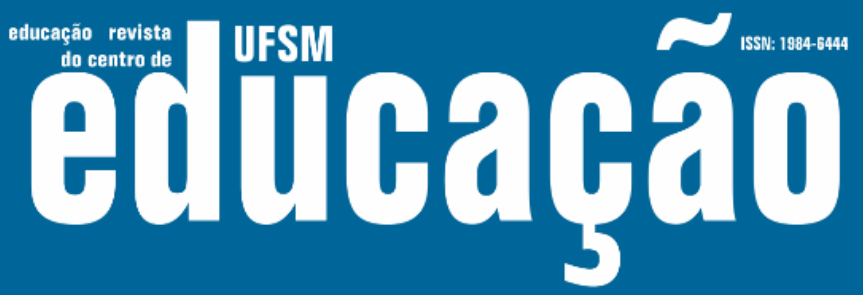

ISSN: 1984-6444 | http://dx.doi.org/10.5902/1984644434409

causas dessa relação, procurando, portanto, uma explicação causal para o resultado de suas ações e/ou interações (CARVALHO, 1999).

Nesta perspectiva de elucidar fenômenos observáveis, professores, alunos e pesquisadores envolvidos com as Ciências procuram explicações dentro daquilo que conhecem ou do que vivenciaram (SILVA; MACHADO; TUNES, 2010). Dessa forma, apesar de muitas vezes o modo de proceder ter semelhanças, o desenvolvimento individual do pensar dentro de um processo investigativo, não está limitado a um único caminho ou método.

Para Silva, Machado e Tunes (2010), ao longo da história as teorias foram desenvolvidas para explicar os fenômenos observados, no entanto, na ciência moderna as teorias desenvolvidas têm um elevado poder de previsão de novos fenômenos, mesmo nunca observados. Quando se realizam atividades experimentais e observam-se determinados fenômenos, geralmente solicita-se aos estudantes que os expliquem. O esclarecimento de um fenômeno utilizando-se de uma teoria é o que se denomina de "relação teoria-experimento, ou seja, é a relação entre o fazer e o pensar" (SILVA; MACHADO; TUNES, 2010, p. 236).

Considera-se que o uso de uma teoria para explicar um fenômeno não significa provar sua veracidade, mas sim testar sua capacidade de generalização. Daí a importância de conhecer a história de alguns conceitos, pois isso permite identificar o contexto em que foram propostos e, principalmente, que fenômenos buscavam explicar. Quanto ao aspecto de capacidade de previsibilidade de uma teoria, a ação de utilizar um laboratório não significa que se está provando a veridicidade da teoria, mas apenas testar sua capacidade de previsão (ROCHA, 2015).

Portanto, a capacidade de previsão e generalização de uma teoria é que pode dar à experimentação no ensino um caráter investigativo. A abordagem ao ensino de ciências por investigação é uma das atuais tendências e que possibilitam contornar os obstáculos e as crenças que limitam seu uso de forma mais eficaz (ROCHA, 2015).

As atividades experimentais investigativas buscam a solução de uma questão que será respondida pela realização de uma ou mais experiências, que podem envolver etapas ou Sequências de Ensino Investigativa (SEI). Assim, uma SEI, deve ter algumas atividades-chave: na maioria das vezes inicia-se por um problema, 


\section{Ism Eutbapga}

ISSN: 1984-6444 | http://dx.doi.org/10.5902/1984644434409

experimental ou teórico, contextualizado, que introduz os alunos no tópico desejado e ofereça condições para que pensem e trabalhem com as variáveis relevantes do fenômeno científico central a ser estudado (MALHEIRO, 2016; ROCHA, 2015; CARVALHO, 2013).

Cabe ressaltar que a experimentação investigativa, de modo equivocado, se pensa requer um laboratório. Entendemos que o uso da experimentação, deve enfatizar a relação teoria-experimento, incorporando a interdisciplinaridade e a contextualização na diversidade de espaços. Nesse sentido, "o material didático aparato experimental, textos, figuras - sobre o qual o problema será proposto precisa ser bem organizado" para que os alunos possam resolvê-los sem se perder, isto é, o material didático deve ser intrigante para despertar a atenção deles, de fácil manejo para que possam manipular e chegar a uma solução sem cansarem (CARVALHO, 2013, p. 10).

As atividades experimentais investigativas incorporam como eixos norteadores o ensinar e o aprender como processos indissociáveis; a não dissociação teoriaexperimento, a interdisciplinaridade, a contextualização e a ciência, tecnologia, sociedade e ambiente como decorrentes dos contextos escolhidos para 0 desenvolvimento dessas atividades (SILVA; MACHADO; TUNES, 2010).

\section{Procedimentos metodológicos}

Este artigo foi construído a partir do aprimoramento de propostas de pesquisas e produções científicas sobre tópicos da experimentação investigativa e o estado do conhecimento em metacognição em um Clube de Ciências. Ao longo de três anos observando, discutindo, acompanhando e realizando atividades em um Clube de Ciências, pudemos observar muitas vezes, a configuração de escolas éticas e políticas educacionais que nos trouxeram elementos para construção de uma tese (em fase de finalização), no sentido de contribuir e aperfeiçoar processos formativos e de expertises no campo do ensino por investigação.

Neste percurso, foram experienciadas e identificadas evidências empíricas da necessidade de relação entre a metacognição e ensino por investigação no desenvolvimento de concepções e atividades experimentais. Entendemos que por 


\section{Autuaŗão}

ISSN: 1984-6444 | http://dx.doi.org/10.5902/1984644434409

meio das práticas experimentais aplicadas, tenciona-se tanto fazer emergir a argumentação entre os alunos, como ter um registro escrito sobre o processo de pensamento dos mesmos no decorrer das discussões realizadas em torno de um experimento e em função deles para a resolução de problemas. Para agregar melhor organização, planejamento e mais informações no sentido de poder relacionar, de fato, os movimentos de construção dos alunos com as situações de metacognição vivenciadas por eles.

Para tanto, valemo-nos de dois referenciais (COMPIANI, 1996; BOUTER; GILBERT, 1995), complementados pelos estudos de Rocha e Malheiro (2018). Com abordagem qualitativa na perspectiva da Análise do Conteúdo - AC (BARDIN, 2009) procuramos caracterizar metodologicamente este trabalho.

Assim, partindo da discussão sobre metacognição e dimensões interativas supracitadas - e ainda nos apoiando nos operadores dos referenciais argumentativos presentes na proposição de SEI (ROCHA; MALHEIRO, 2018) - empreendemos a construção de um instrumento de análise de categorias interativas dialógicas na experimentação investigativa.

\section{Nossa proposta de categoria}

O professor eficaz, para atuar no século XXI, deve ser reflexivo e ir muito além de dominar bem seu conteúdo e ter uma boa didática. Deverá possibilitar aulas diferenciadas que incluam tanto abordagens didáticas e cognitivas, quanto metacognitivas (LOCATELLI, 2014). Assim, possibilitar ricos momentos de aprendizagem, sobretudo a reelaboração ou a reflexão sobre ela, são mágicos momentos de meta-aprendizagem, em que se pode observar um envolvimento ativo do aprendiz no processo de aprendizagem.

Considera-se que a avaliação é importante para o processo de aprendizagem. Aqui, entendemos que a avaliação como diagnóstico do processo é fundamental, pois a partir dela pode-se proceder à tomada de decisões para a construção e reconstrução dos conceitos que precisam ser aprimorados (ROCHA; MALHEIRO; TEIXEIRA, 2018). 


\section{Dism

ISSN: 1984-6444 | http://dx.doi.org/10.5902/1984644434409

Ressalta-se que a literatura sobre estratégias de ensino e aprendizagem é extremamente ampla (CARVALHO, 2013; ROCHA; MALHEIRO, 2018; SILVA; MACHADO; TUNES, 2010), porém estudos, apoiando-se no potencial metacognitivo da interação dialógica na experimentação investigativa, são escassos. Os estudos no Clube de Ciências mostram que as interações dialógicas, por sua organização em SEI, se constituem em interessante alternativa para fazer emergir formas de pensamento sofisticadas, como as que definem um pensamento metacognitivo crítico e reflexivo (ROCHA; MALHEIRO, 2018).

Vários aspectos importantes, relativos à experimentação investigativa no ensino são abordados, levando em consideração o conteúdo programático desenvolvido nas escolas em que os alunos estudam. Destacamos que o Clube adota uma abordagem didática, que considera a proposta de Carvalho et al, (2009) com adaptações de tese de Rocha (2018), (Figura 2).

Figura 2 - Proposta de SEI

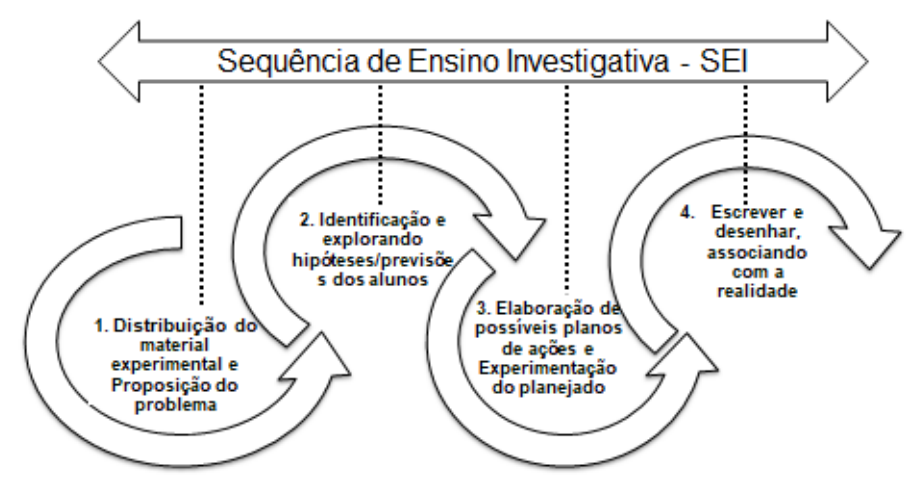

Fonte: Rocha (2018).

Por meio da SEI é que reside o grande potencial do Clube como espaço de educação científica não formal (GONN, 2006) no desenvolvimento de atividades que permitem metacognição. Portanto, é importante viabilizar um instrumento de análise (Figura 3) que ajude a compreender de que maneira se estabelecem interações dialógicas e a construção de esquemas argumentativos manifestados por um grupo de professores e alunos participantes de um Clube de Ciências, ao buscar soluções para um problema real, com base na experimentação investigativa. 


\section{Fism

ISSN: 1984-6444 | http://dx.doi.org/10.5902/1984644434409

Nossa proposta busca analisar qualitativamente processos de interações discursivas no ensino de Ciências com pressupostos metodológicos, aqui interpretados como próximos aos de uma pesquisa participante.

Ao plano de análise dos dados, inspirado principalmente nas propostas de Compiani (1996) e Boulter e Gilbert (1995), adaptamos um instrumento de análise visando propiciar um maior detalhamento das ações do professor na busca por uma construção de interações dialógicas mais refinadas e estruturadas por parte de seus alunos e, portanto, possibilitando uma compreensão de diferentes aspectos relacionados à metacognição e interação em atividades experimentais investigativas.

Figura 3 - Plano de Análise dos dados do discurso na experimentação investigativa

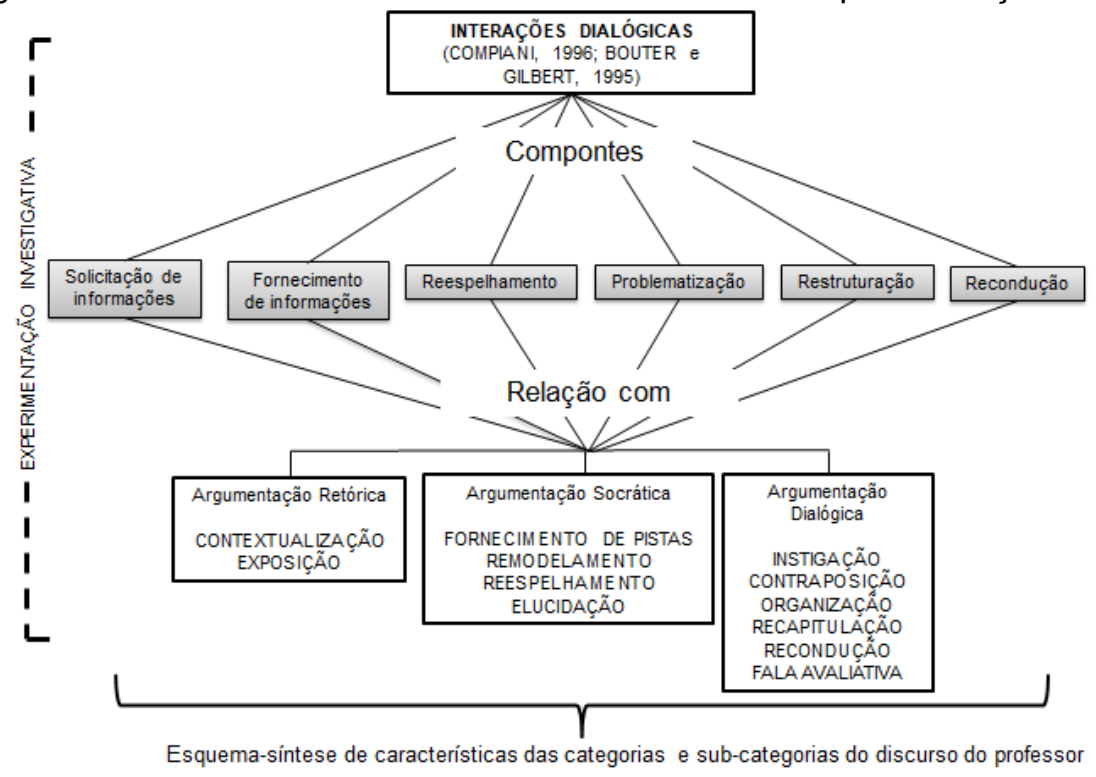

Fonte: Com base em Compiani (1996) e Bouter; Gilbert (1995).

Conforme Monteiro e Teixeira (2004), com base em amplas interações discursivas em sala de aula, elaboram-se categorias que permitem compreender melhor o papel da fala dos alunos e do professor em sala de aula. A solicitação de informações pode ser caracterizada pela necessidade que apresentam os sujeitos interativos em alcançar explicações convincentes, intervindo de forma categórica nos rumos do diálogo. Podem ser do tipo explicação, que é solicitada quando não houver ideias que explicitem um determinado fato e clarificação, que é solicitada quando falta clareza às ideias que foram expostas. 


\section{Wusm EItlagha}

ISSN: 1984-6444 | http://dx.doi.org/10.5902/1984644434409

O Fornecimento de Pistas define-se pela ação indutiva docente sobre o raciocínio dos alunos, feita por meio de exposição direta de ideias ou por intermédio de dicas, que são definidas pela atitude do professor em oferecer elementos que sustentem o aluno numa trajetória de raciocínio, previamente traçada, visando conduzi-lo à resolução de um problema. Os autores destacam ainda uma postura intermediária entre esses dois tipos de informações; trata-se do Remodelamento.

Nesse tipo de postura, o professor chama atenção para alguns pontos de vista, apresentado pelos próprios alunos, oferecendo informações que preenchem lacunas conceituais, dando contornos sobre ideias e aproximando-a da visão científica. O Reespelhamento é a postura adotada pelo professor para encorajar a fala do aluno.

A Problematização indica uma maneira propositada, normalmente do professor, mas que pode partir também do aluno, de investigar, estudar, provocar reflexões em busca de respostas para determinado problema. Nessa categoria, os autores incluem as contraposições, que são ideias colocadas com o objetivo de destacar alguma contradição ou gerar conflitos importantes para o desenvolvimento da aula.

A reestruturação é a atitude de reorganização das proposições feitas durante as interações discursivas, constituindo-se como organização final ou parcial das opiniões manifestadas e que foram discutidas sobre determinado assunto. Quando se têm a sistematização final, utilizada a fim de generalizar ideias para encerrar a questão, temos uma Recapitulação.

A Recondução caracteriza-se pela retomada, por parte do professor, da pertinência das discussões que se estabelecem em sala de aula. Monteiro e Teixeira (2004) destacam que a dimensão de pertinência permite ao docente avaliar os rumos do discurso, ou seja, admite perceber se o diálogo está evoluindo ou não dentro do objetivo principal em estudo. Ao constatar derivações não pertinentes, o professor pode intervir recolocando-o nas discussões.

Frente às categorias descritas, acredita-se que a abordagem qualitativa seja a mais adequada para esta proposição, pois propõe uma relação intrínseca com a interação estudada, permitindo que o pesquisador tenha um contato prolongado com o seu objeto de estudo, visão holística do fenômeno estudado e observe os fenômenos que influenciam o seu contexto. Essas situações são essenciais para que o 


\section{Autuaŗão}

ISSN: 1984-6444 | http://dx.doi.org/10.5902/1984644434409

pesquisador possa analisar e compreender, de forma profunda, o seu objeto de estudo.

Os acordos metacognitivo negociados através das interações dialógicas, estabelecida na SEI da experimentação investigativa, dão a possibilidade de conteúdos ou termos técnicos, já estabelecidos em língua, saírem da mera diacronização e tornarem-se objetos de sentido nos discursos. Estes acordos consideram às dicas metacognitivas propostas por Locatelli (2014), que dizem respeito à necessidade real de aprendizagem: distinguir informações relevantes das irrelevantes; conexão entre os conceitos; fazer perguntas a si mesmo o tempo todo; resumir os conceitos e formação de grupos de estudo.

Considerando a resolução de problemas, destacamos que é necessário saber distinguir informações relevantes das irrelevantes. Vale mencionar que, em muitos casos, para que a experimentação investigativa possa trazer resultados mais consolidados do ponto de vista metacognitivo, outras perguntas podem ser feitas e associadas ao problema central (ROCHA; MALHEIRO, 2018).

Nesta conexão, considerando os conhecimentos conceituais se recomenda, concentração e atenção para a eficácia metacognitiva. É uma estratégia para o levantamento do que já se tem como alicerce para as discussões que vão ocorrer e, por isso, sua importância. É um momento de tomada de consciência sobre dados à disposição.

Ficar se questionando reiteradamente é um passo ao reconhecimento das ações realizadas. Neste momento, são reconhecidas as variáveis que atuam no fenômeno, construindo ou reconstruindo mentalmente tomadas de consciência e que são relevantes para a metacognição. Assim, recomenda-se que resuma os conceitos, para o entendimento, ao menos básico, do que está sendo estudado, monitorando o conhecimento e permitindo a regulação da aprendizagem.

Finalmente, a formação de grupos de estudo de até cinco alunos é fundamental para o desenvolvimento de diálogos. Pois, favorece que todos tenham a oportunidade de manipular materiais didáticos, construírem relações entre as variáveis, análise de condições limites de conhecimento prévios, evitando dispersões. 


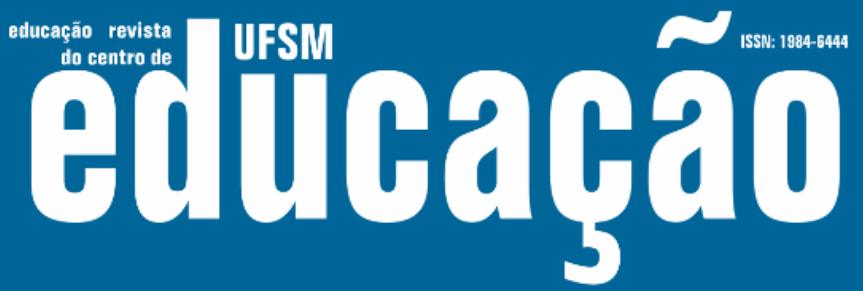

ISSN: 1984-6444 | http://dx.doi.org/10.5902/1984644434409

Os componentes de interações dialógicas, ao se relacionarem com a argumentação, provocam a constituição dos aspectos de metacognição, tanto do conhecimento da cognição, como de sua regulação. Em consequência, estas relações se aproximam, sem dúvida, de um dos maiores objetivos da educação, tanto básica como superior: o desenvolvimento da autonomia no estudante, conduzindo-o a saberes de como aprendem e buscando conhecimentos nos mais diversos contextos (ROCHA; MALEHIRO, 2018; DUSCHL, 1998).

Não há razão em realizar atividades experimentais, quaisquer que sejam os assuntos, se estes não fizerem sentido e parte da vida dos alunos. Do que vale aprender sem apreender? De que vale significar sem ter sentido? De que vale saber por saber, pelo simples fato de mencionar? Os acordos interativos trabalhados e negociados em função de um sentido metacognitivo é que vão dar razão as argumentações retórica, socrática ou dialógica (COMPIANI, 1996).

Percebe-se então, que a metacognição vai muito além de pensar sobre o seu pensamento, ou seja, a cognição sobre a cognição. Envolve processos interativos de monitorar, avaliar e autorregular a aprendizagem (LOCATELLI, 2014). As relações estabelecidas nos processos do instrumento proposto reafirmam que a metacognição possibilita uma análise gradativa de mais metacognição, verificando as habilidades de aprender a aprender e da condução da aprendizagem.

Por meio do instrumento proposto, acreditamos que os aspectos que podem ser considerados para potencializar a metacognição, ao encaminhar uma resolução para situações problemas, permitem: estabelecer conceitos com significados, foco nos procedimentos de tarefas, separação de informações relevantes e irrelevantes, conexões entre fatos, fazer perguntas a si mesmo, fazer resumos e formar grupo colaborativos de estudos.

Consoante a estas reflexões, estabelecemos categorias e subcategorias de análises, inspiradas em Compiani (1996), que possibilita caracterizar, de maneira mais específica, o dizer do professor a partir das três categorias gerais (argumentação retórica, socrática e dialógica), retomando as definições que Monteiro e Teixeira (2004) e Boulter e Gilbert (1995) apresentam para cada uma dessas três categorias gerais (Figura 4). 


\section{- Tusm

ISSN: 1984-6444 | http://dx.doi.org/10.5902/1984644434409

Figura 4 - Categorização do discurso do professor na experimentação investigativa

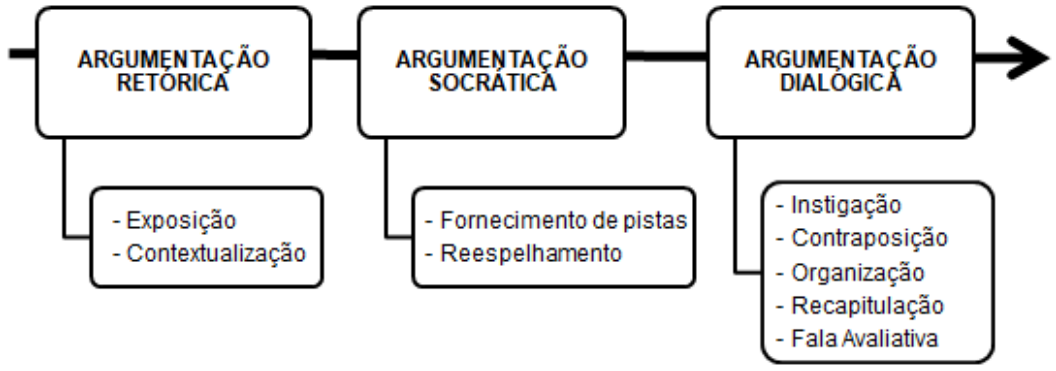

Fonte: (Compiani, 1996; Bouter; Gilbert, 1995). Adaptado.

$\mathrm{Na}$ argumentação retórica, a exposição é o discurso docente caracterizado pela apresentação de ideias que possam subsidiar o aluno na compreensão de um determinado assunto.

Esse encaminhamento não é desencadeado por questões propostas explicitamente pelos alunos, mas é organizado pelo professor, quando este julga que os alunos necessitam de determinadas orientações para realizar as tarefas que ele determinou. Aqui, como na contextualização, o aluno desempenha um papel passivo; é o professor que toma a iniciativa e conduz os rumos da aula (BOULTER; GILBERT, 1995).

Estas categorias e subcategorias de análise tem como suporte instrumental qualquer tipo de mensagem e formas de expressão dos sujeitos sociais, resultando em um conhecimento não linear. Assim, essas categorias permitem compreender criticamente o sentido das falas dos sujeitos, os significados metacognitivos explícitos ou ocultos.

Sendo assim, as subcategorias baseadas na argumentação socrática, podem caracterizar mais detalhadamente esse padrão discursivo do professor em sala de aula: Fornecimento de Pistas, Reespelhamento, Remodelamento, Elucidação. O Fornecimento de Pistas, ratificando o já explicitado anteriormente, é a fala do professor que visa dirigir o raciocínio dos alunos. É feita por meio de uma explicação ou por intermédio do oferecimento de elementos que o sustentem numa trajetória de raciocínio, que possa conduzi-lo à resposta desejada ou até mesmo por intermédio de uma sucessão de perguntas que levem os alunos a determinadas conclusões (MONTEIRO; TEIXEIRA, 2004). 


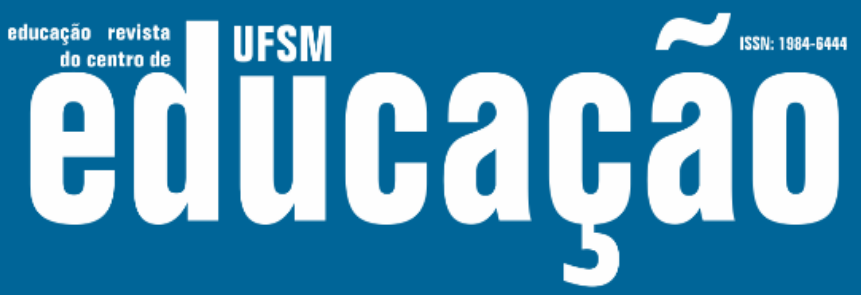

ISSN: 1984-6444 | http://dx.doi.org/10.5902/1984644434409

Reespelhamento é a fala do professor que autoriza ou não as ideias e a fala dos alunos. Investido da autoridade discursiva, o professor, ao repetir com ênfase ou mesmo gesticulando positivamente, atribui legitimidade à ideia do aluno, inibindo posições em contrário. Entretanto, a partir dessa mesma autoridade, o professor pode, com uma negativa, ou mesmo com uma espera por outras respostas, indicar para o aluno que suas ideias não foram aceitas como corretas.

Para Compiani (1996) e Boulter e Gilbert (1995), Remodelamento é a fala do professor que destaca algumas ideias, apresentadas pelos alunos, que ainda carecem de maior precisão e detalhes; oferece informações que preenchem lacunas conceituais dos alunos, dando contornos precisos e nítidos a uma ideia, aproximandoa da visão científica. São ajustes feitos pelo professor a partir das ideias construídas pelos alunos. Elucidação é a fala do professor motivada por questões colocadas pelos alunos; tem por objetivo tornar clara algumas ideias que foram expostas, mas não foram inteligíveis para alguns estudantes.

Finalmente, Bouter e Gilbert (1995) categorizam a fala do professor a partir de um terceiro tipo de discurso docente. Para esses autores, a categoria argumentação dialógica destaca-se como sendo as atitudes do professor que incentivam e regulam o compartilhamento de ideias envolvidas no processo de ensino e de aprendizagem, a partir da confrontação de opiniões expostas por todos os envolvidos.

Assim concorda-se com Monteiro e Teixeira (2004) ser conveniente caracterizar essa categoria a partir das seguintes subcategorias: Instigação, Contraposição, Organização, Recapitulação, Recondução e Fala Avaliativa.

A Instigação caracteriza-se quando o professor objetiva estimular os estudantes a apresentarem suas ideias, dando início à interação dialógica em sala de aula.

Os autores concebem que a Contraposição como o momento em que, na oratória do professor, percebe-se que o mesmo dá ênfase a possíveis contradições nas ideias manifestadas pelos estudantes ou quando apresenta argumentos que possam gerar confrontação de opiniões no ambiente de sala de aula.

A Organização destaca-se quando o docente organiza ideias que emanaram das considerações postuladas pelos estudantes, objetivando a refletirem sobre a 


\section{Authabูão}

ISSN: 1984-6444 | http://dx.doi.org/10.5902/1984644434409

aproximação e o afastamento das ideias principais que estão em discussão, o que pode desencadear novas interações dialógicas em sala de aula. É o momento que propicia a metacognição entre as ideias colocadas na discussão.

A Recapitulação surge quando o professor busca fazer uma síntese dos conteúdos que foram abordados, no sentido de provocar reflexões acerca das opiniões que já foram apresentadas pelos alunos. É o momento de se fazer uma síntese metacognitiva de tudo o que foi discutido, com o intuito de concluir o debate (ROCHA; MALHEIRO, 2018).

A Recondução surge quando a oratória docente busca retomar o desenvolvimento metacognitivo relativo às discussões que surgiram.

Por fim, a fala Avaliativa é a discurso do professor pela busca da lógica utilizada pelo aluno ao fazer determinada afirmação. "Essa postura docente investiga os motivos que levaram o aluno a externar uma determinada opinião" (MONTEIRO; TEIXEIRA, 2004, p. 248).

Este procedimento e processamento da construção dos dados procura reduzir o volume amplo de informações contidas em uma interação dialógica a algumas características particulares ou categorias conceituais que permitam passar dos elementos descritivos à interpretação ou investigar a compreensão dos sujeitos no contexto experimental investigativo em que produzem metacognição.

Mediante tal procedimento de análise, Rocha e Malheiro (2018) consideram que os depoimentos podem ser classificados em categorias visando a uma análise fidedigna das interações entre metacognição e pensamento crítico, que emerge o próprio pensamento. As possíveis categorias estabelecidas a priori do trabalho de campo, na fase exploratória de pesquisa, exigem uma fundamentação teórica sólida sobre experimentação investigativa em espaços não formais de educação científica.

Outro aspecto relevante é o apoio da técnica de vídeo gravação, que para Carvalho (2004), tem se mostrado altamente produtiva, quer nas pesquisas em que o enfoque é o professor, quer nas investigações que procuram entender como se constroem os conhecimentos científicos durante as aulas, pois a filmagem das aulas possibilita estudar o detalhamento do processo de interações entre professor e aluno. 


\section{Dism Autuabat

ISSN: 1984-6444 | http://dx.doi.org/10.5902/1984644434409

Já com os instrumentos e técnicas de pesquisa viabilizada, durante as observações das atividades executadas no Clube de Ciências, por captação de imagem com aparelho smartphone e filmadora HD localizados estrategicamente no espaço de sala de aula, se permite captação de imagens difusa dos sujeitos de pesquisa.

As atividades, posteriormente, devem ser transcritas e organizadas destacando para análise transcrições dos aspectos de interações dialógicas na experimentação investigativa. É importante salientar que foi feita a disponibilização do Termo de Consentimento Livre e Esclarecido - TCLE, a todos os participantes para autorização de gravações se faz necessária.

Ainda, no processo de análise utiliza-se a seleção de transcrição de falas entre professores e alunos, selecionando turnos que se aproximem dos aspectos de características das categorias propostas no discurso dos professores como unidades de análise de acordo com a análise do conteúdo (BARDIN, 2009; FAIRCLOUGH, 2003) em fases: a pré-análise; a exploração do material; o tratamento dos resultados, a inferência e a interpretação com representação de quadros, figuras e tabela, baseando-se em espirais de reflexão e ação, que inclui aclarar e diagnosticar uma situação prática ou um problema prático que se quer melhorar ou resolver; formular estratégias de ação; desenvolver essas estratégias e avaliar sua eficiência; ampliar a compreensão de situações metacognitivas.

\section{Considerações Finais}

Em linhas gerais, foi possível sinalizar o papel de um instrumento de análise em que a argumentação na experimentação investigativa desempenha favorecimentos para os processos metacognitivos. Tal instrumento se apoia na discussão que uma SEl favorece a um desenvolvimento gradual de ter consciência e controlar, tanto o processo argumentativo como o metacognitivo, ao qual a uma atividade se propõe. 


\section{F HEM elithabá}

ISSN: 1984-6444 | http://dx.doi.org/10.5902/1984644434409

Neste artigo, a metacognição implica estar atento aos pontos fortes e fracos de nosso próprio funcionamento intelectual e aos tipos de erros de raciocínio que normalmente cometemos.

Nesse sentido, a seleção, adaptação ou criação de instrumentos devem priorizar a confiabilidade e validade. Não é possível confiar em uma forma de análise que não tenha clareza. É necessário esclarecer conforme Sampiere et al. (2006), que em uma pesquisa, existem duas opções com relação ao instrumento de análise: Escolher um já desenvolvido e disponível, que se adapte às necessidades do estudo em particular e construir um novo de medição de acordo com a técnica apropriada para isso.

Em ambos os casos, é importante demonstrar a confiabilidade e validade dos mesmos. Defendemos, portanto, a necessidade de incentivos a uma arquitetura de análise metacognitivo do próprio pesquisador em sua formação sólida, voltados para alfabetização científica e com foco no trabalho com a modalidade interativa, como se busca no Clube de Ciências.

Como potencial de continuidade deste estudo, dois aspectos são fundamentais: O planejamento da atividade experimental investigativa, que se constitui um aspecto a ser mais explorado, sendo importante sua compreensão microscópica, macroscópica e representacional dos fenômenos e, consequentemente, na metacognição. Outro aspecto, de acordo com Rocha e Malheiro (2018), refere-se às possíveis interações dialógicas do grupo com o desenvolvimento cognitivo individual.

Do ponto de vista metodológico, os dados observacionais podem ser triangulados com outras análises de dados, em uma abordagem de estudos descritivos e exploratórios levando em consideração fatores epistemológicos e pedagógicos.

A proposição aqui apresentada, que é adaptável e flexível a quem pesquisa esta temática, possibilita potencializar os aspectos metacognitivos explícitos ou ocultos. Acreditamos na importância da atuação de um pesquisador crítico, ético, reflexivo, criativo, dinâmico, na compreensão da realidade social e de contradições, no enfrentamento das diversas expressões da questão que envolva interações 


\section{F WsM Futbabुa}

ISSN: 1984-6444 | http://dx.doi.org/10.5902/1984644434409

dialógicas, que se manifestam no cotidiano de ensino, com um sentido original e confiável voltado para contribuir para a construção de conhecimentos.

Finalizamos, acreditando que ao se refletir sobre a possibilidade de desenvolvimento metacognitivo a partir das situações de experimentação investigativa, resultados muito interessantes ao objetivo deste estudo podem ser encontrados para o aperfeiçoamento de abordagens didáticas nos diversos espaços de educação científica. Contudo, se faz necessário está aberto às mudanças e inovações, replicando boas ideias que são consolidadas, e, criando outras mais originais.

\section{Referências}

ALMEIDA, A. M. Papel do Trabalho Experimental na Educação em Ciências. Comunicar Ciências. Ministério da Educação - Portugal. Departamento de Ensino Secundário, ano I, n. 1, 1998.

AXT, R. O papel da experimentação no ensino de ciências. In: MOREIRA, M. A.; AXT, R. Tópicos em Ensino de Ciências. Porto Alegre: Sagra, 1991.

BARDIN, L. Análise de conteúdo. Lisboa, Portugal. Edições 70. LDA, 2009.

BOULTER, C. J.; GILBERT, J. K. Argument and science education. In: Costello, P.J. M. e Mitchell, S. (edts). Competing and Consensual voices: the theory and pratice of argument. Multilingual Matters LTD, cap.6, p. 84-98, 1995.

BROWN, N. The development of a questionnaire assessing metacognitive patterns of students majoring in accounting in higher education. Accounting education: an international jornal, v. 15, n. 3, p. 301-323, 2006.

CARVALHO, A. M. P. O ensino de ciências e a proposição de sequências de ensino investigativas. In: CARVALHO, A. M. P. (Org.) Ensino de Ciências por Investigação: Condições para implementação em sala de aula. São Paulo: Cengage Learning, $p$. 1-20, 2013.

CARVALHO, A. M. P. et al. Ciências no Ensino Fundamental: o Conhecimento Físico. São Paulo: Scipione, 2009.

CARVALHO, A. M. P. Ensino de Ciências: unindo a pesquisa e a prática. São Paulo: Editora Thompson, 2004.

CHALMERS, A.F. O que é ciência, afinal? São Paulo, Brasiliense, 1999. 


\section{TH Wu \\ ISSN: 1984-6444 \\ Entuaḩa}

ISSN: 1984-6444 | http://dx.doi.org/10.5902/1984644434409

CHIAROL, S.; AQUINO, K. A. S. Argumentação na sala de aula e seu potencial metacognitivo como caminho para um enfoque CTS no ensino de química: uma proposta analítica. Educ. Pesqui., São Paulo, v. 43, n. 2, p. 411-426, 2017.

CLEOPHAS, M. G.; FRANCISCO, W. Metacognição e o ensino e aprendizagem das ciências: uma revisão sistemática da literatura (RSL). Revista Amazônia.

COMPIANI, M. As geociências no ensino fundamental: um estudo de caso sobre o tema a formação do Universo. 1996. Tese de Doutorado. Faculdade de Educação. Universidade Estadual de Campinas. Campinas, São Paulo.

DUSCHL, R. La valorización de argumentaciones y explicaciones: promover estratégias de retroalimentación. Enseñanza de Las Ciências, v. 16, n. 1, p.3-20, 1998.

FAIRCLOUGH, N. Analysing discourse: textual analysis for social research. Londres: Routledge, 2003.

FLAVEL, J. H. Metacognition and cognitive monitoring: A new área of cognitivedevelopmental Inquiry. American Psychologist, v. 34, p. 906-911, 1979.

GIRASH, J. Metacognition and instruction. In: BENASSI, V.; OVERSON, C.; HAKALA, C. (Org.). Applying Science of learning in education. Washington, D. C.: Society for the Teaching of Psychology, p. 152-168, 2014.

GONÇALVES, T. V. O. Pontes entre Universidade e $01^{\circ}$ e $2^{\circ}$ graus: de Clubes de Ciências na experiência do NPADC/UFPA. Caderno Catarinense de Ensino de Física, Florianópolis, v. 10, n.1, p. 95-99, 1993.

GONÇALVES, F. P.; GALIAZZI, M. C. A naturea das atividades experimentais no Ensino de Ciências: um programa de pesquisa educativa nos cursos de licenciatura. In: MOREIRA, R. (Orgs.). Educação em Ciências: produção de currículos e formação de professores. 2ªed. ljuí: Ed. Unijuí, 2006.

GOHN, M. G. Educação não-formal, participação da sociedade civil e estruturas colegiadas nas escolas. Ensaio: aval. pol. públ. Educ., Rio de Janeiro, v.14, n.50, p. 27-38, 2006.

HODSON, G. J. Laboratory work as scientific method: three decades of confusion and distortion. Journal of Curriculum Studies, v. 28, n. 2, 1996.

KELLY, G. J. Inquiry, activity and epistemic practice. In Duschl, R. A.,e Grandy, R. E. (eds.) Teaching Scientific Inquiry: recommendations for resarch and impementation. Rotterdam, Holand: Taipei Sense Publishers, p. 288-291, 2008.

LOCATELLI, S. W. Tópicos de metacognição: para aprender a ensinar melhor. $1^{1}$ ed. Curitiba: Appris, 2014. 


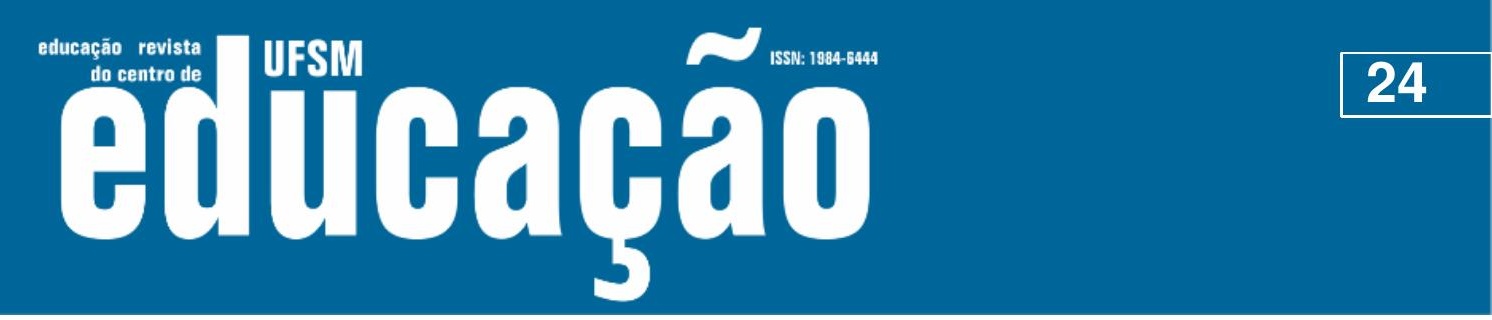

ISSN: 1984-6444 | http://dx.doi.org/10.5902/1984644434409

LUCA, A. G.; SANTOS, S. A. A experimentação contextualizada e interdisciplinar como promotora da escrita e da leitura na construção de conceitos científicos. II Colóquio Luso-Brasileiro de Educação - II COLBEDUCA. Joinvile, SC. 2016.

MALHEIRO; ROCHA. Clube de Ciências prof. Dr. Cristovam W. P. Diniz e o ensino investigativo no município de Castanhal/Pa. In: EnECI - Encontro de Ensino de Ciências por Investigação. Universidade de São Paulo - USP/LaPEF-FEUSP. 2017.

MALHEIRO. Atividades experimentais no ensino de ciências: limites e possibilidades. ACTIO: Docência em Ciências, v. 1, n. 1, p. 107-126, 2016.

MALHEIRO; FERNANDES P. O recurso ao trabalho experimental e investigativo: Percepções de professores de ciências. Investigações em Ensino de Ciências, v. 20, n.1, p. 79-96, 2015.

MATHABATHE, K. C.; POTGIETERB, M. Metacognitive monitoring and learning gain in foundation chemistry. Chemistry Educational Research Practice, v. 15, p. 94-104, 2014.

MEDEIROS, E. F.; SILVA, M. G. L.; LOCATELLI, S. W. A argumentação e o potencial metacognitivo de uma atividade experimental baseada na POA (previsão-observaçãoargumentação. Amazônia Revista de Educação em Ciências e Matemática, v.14, n.29, p. 27-42, 2018.

MONTEIRO, M. A. A. e TEIXEIRA, O. P. B. Uma análise das interações dialógicas em aulas de ciências nas séries iniciais do ensino fundamental. Investigações em Ensino de Ciências. Publicação eletrônica, v.9, n.3, p. 243-263, 2004.

OLIVEIRA, M. A. de. Alfabetização científica no clube de ciências do ensino fundamental: uma questão de inscrição. Revista Ensaio, Belo Horizonte, v.12, n. 2, p.11-25, 2010.

PORTILHO, E. M. L.; MEDINA, G. B. K. Metacognition as Methodology for Continuing Education of Teachers. Creative Education, 7, 1-12, 2016. Disponível em: < http://www.metacognicao.com.br/wp-content/uploads/2016/01/Clique-Aqui-2.pdf> Acesso em: 29 set. 2016.

PRÁ, G.; TOMIO, Clube de Ciências: Condições de produção da pesquisa em educação científica no Brasil. Alexandria, Revista de Educação em Ciência e Tecnologia, v.7, n. 1, p. 179-207, 2014.

PRAIA. P.; CAHAPUZ, A.; GIL-PÉREZ, D. A Hipótese e a experiência científica em Educação Em Ciência: contributos para uma reorientação epistemológica. Ciência \& Educação, v. 8, n. 2, p. 253-262, 2002.

ROCHA. Desenvolvimento profissional de professores mestrandos em perspectivas do ensino por investigação em um clube de ciências. Tese (em 


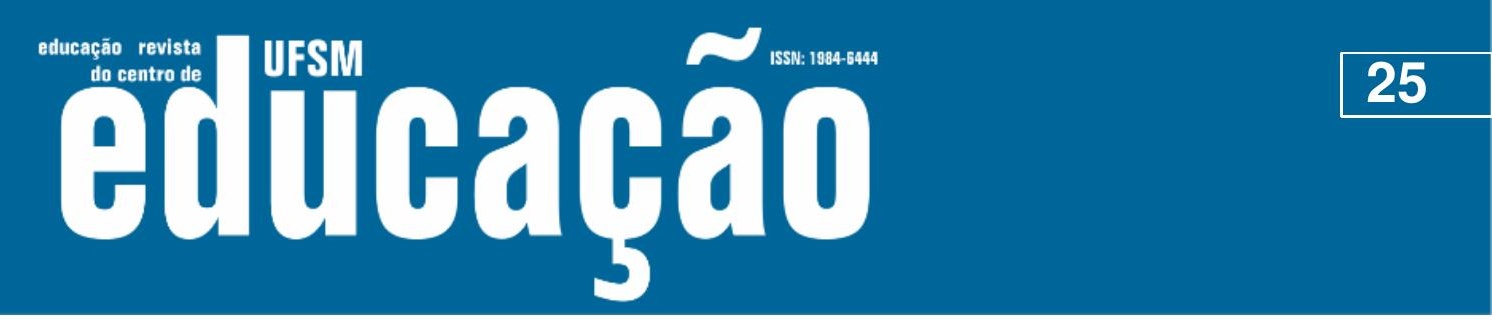

ISSN: 1984-6444 | http://dx.doi.org/10.5902/1984644434409

finalização). Programa de Pós-Graduação em Educação em Ciências e Matemáticas. Universidade Federal do Pará. Belém. Pará.

ROCHA; MALHEIRO. Interações dialógicas na experimentação dialógica na experimentação investigativa em um Clube de Ciências: proposição de instrumento de análise metacognitivo. Amazônia Revista de Educação em Ciências e Matemática, v.14, n.29, p. 193-207, 2018.

ROCHA; MALHEIRO; TEIXEIRA, O. P. B. Formação profissional docente e ações colaborativas com atividades investigativas no clube de ciência Prof. Dr. Cristovam Diniz. Anais...I Encontro de Educação em Ciências e Matemática. Universidade Federal de São Carlos - UFSCar/Bauru. São Paulo. 2018.

ROCHA; MALHEIRO. Clube de Ciências e a experimentação investigativa: estimulando a alfabetização científica de alunos no ensino fundamental. Anais... XVII ENEC. Encontro Nacional de Educação em Ciências e I SIEC - Seminário Internacional em Ciências. Escola Superior de Educação do Instituto Politécnico de Viana do Castelo. Portugal. 2017.

ROCHA; ALTARUGIO, M. H.; MALHEIRO. Educação química e características de ensino investigativo em escolas públicas da região norte do Brasil. Educação Química Em Punto de Vista, v.1. n.1. p. 41-58, 2017.

ROCHA. Ensino da química na perspectiva investigativa em escolas públicas do município de Castanhal-Pará. 2015. 120f. Dissertação (Mestrado). Universidade Federal do ABC. Santo André. São Paulo.

SAMPIERI, R. H.; COLLADO, C. F.; LUCIO, P. B. Metodologia de pesquisa. 3. ed. São Paulo: McGraw-Hill, 2006.

SASSERON, L. H.; DUSCHL, R. A. Ensino de ciências e as práticas epistêmicas: o papel do professor e o engajamento dos estudantes. Investigação em Ensino de Ciências, v. 21, n. 2, p. 52-67, 2016.

SASSERON, L. H.; DUSCHL, R. A. Interações discursivas e investigação em sala de aula: o papel do professor. In: CARVALHO, A.M.P. (Org.) Ensino de ciências por investigação: condições para implementação em sala de aula. São Paulo: Cengage Learning, 2013.

SEDANO, L.; CARVALHO, A. M. P. Ensino de ciências por investigação: oportunidades de interação social e sua importância para a construção da autonomia moral. Alexandria, R. Educ. Ci. Tec., Florianópolis, v.10, n.1, p.199-220, 2017.

SILVA, A. A. B. Interações Discursivas em um Curso de Férias: A constituição do conhecimento científico sob a perspectiva da Aprendizagem Baseada em Problemas. 89f. Dissertação (Mestrado em Educação em Ciências). Belém (PA): IEMCI/UFPA, 2015. 


\section{Autนaดูลิ}

ISSN: 1984-6444 | http://dx.doi.org/10.5902/1984644434409

SILVA, R. R. da; MACHADO, P. F. L; TUNES, E. Experimentar sem medo de errar. In: Ensino de química em Foco. (Org.) SANTOS, W. L. e MALDANER, O. A., ed. Unijuí, cap. 9, p. 231261, 2010.

SILVA, A.; ZANON, L. B. A Experimentação no Ensino de Ciências. SCHNETZLER, R. P.; ARAGÃO, R. M. R. (Org.). Ensino de Ciências: Fundamentos e Abordagens. Piracicaba: UNIMEP, p. 120-153. 2000.

WHITE, R. T. Metacognition. In: KEEVE, J. P. (Ed.). Educational Research, Methodology and measurement: na international Handbook. Oxford: Pergamon, 1988. p. $70-75,1988$.

\section{Agradecimento}

O presente trabalho foi realizado com apoio da Coordenação de Aperfeiçoamento de Pessoal de Nível Superior - Brasil (CAPES) - Código de Financiamento 001.

\section{Correspondência}

Carlos Jose Trindade da Rocha - Doutorando da Universidade Federal do Pará (UFPA), Belém, Pará, Brasil.

João Manoel da Silva Malheiro - Professor doutor da Universidade Federal do Pará (UFPA), Belém, Pará, Brasil.

Universidade Federal do Pará (UFPA), Programa de Pós-graduação em Educação em Ciências e Matemática. Rua Augusto Côrrea, 01 - Guamá, CEP: 66075-110. Belém, Pará, Brasil.

E-mail: carlosjtr@hotmail.com - joaomalheiro@ufpa.br

iD ORCID: https://orcid.org/0000-0002-2495-7806

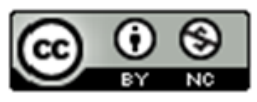

This work is licensed under a Creative Commons Attribution-NonCommercial 4.0 International (CC BY-NC 4.0) 